\title{
СРАВНИТЕЛЬНЫЕ РИСУНКИ КАК СПОСОБ ЭФФЕКТИВНОГО РАЗВИТИЯ У УЧАЩИХСЯ ИЗОБРАЗИТЕЛЬНОЙ ГРАМОТЫ ПО ЖИВОПИСИ В ДЕТСКОЙ ХУДОЖЕСТВЕННОЙ ШКОЛЕ
}

Тарамова Марьям Юсуповна магистр

Художественного образования Научный руководитель: Юсупхаджиева Татьяна Васильевна к.п.н., доцент ФГБОУ ВО «Чеченский государственный педагогический университет»

\begin{abstract}
Аннотация: В данной статье рассматриваются способы решения проблем в формировании развития изобразительной грамоты путем использования сравнительных рисунков в живописи, в процессе обучения в детской художественной школе. Также выделяются преимущества использования сравнительных рисунков как эффективный наглядный метод обучения в живописи.

Ключевые слова: наглядный метод, сравнительные рисунки, педагог, ученик, изобразительная грамота, живопись.

\section{COMPARATIVE DRAWINGS AS A WAY TO EFFECTIVELY DEVELOP STUDENTS' VISUAL LITERACY IN PAINTING AT A CHILDREN'S ART SCHOOL}

\section{Taramova Mariam Yusupovna Yusupkhadzhieva Tatiana Vasilyevna}

\begin{abstract}
This article discusses ways to solve problems in the formation of the development of visual literacy through the use of comparative drawings in painting, in the process of studying at a children's art school. The advantages of using comparative drawings as an effective visual method of teaching in painting are also considered.
\end{abstract}

Key words: visual method, comparative drawings, teacher, student, visual literacy, painting. 
В детской художественной школе, в процессе изучения изобразительной грамоты в живописи, некоторые педагоги задаются вопросом, как донести до учеников смысл преподаваемого материала, как научить правильно и уверенно использовать его в процессе занятий по живописи, чтобы успешно развить необходимые навыки и умение.

Для решения поставленной задачи в обучении живописи педагоги опираются на разработку подходящего метода с помощью научной и методической литературы. Также есть и готовые методы. Например, в процессе обучения живописи самый подходящий метод - это наглядный (реконструкция, фото, картинки, рисунки и т.д.). Наглядный метод можно дополнить и обогатить - внести список использования сравнительных рисунков. Сравнительные рисунки помогут учащимся значительно расширить знание данной темы. Поскольку сравнение является самым эффективным способом развития творческой и умственной деятельности.

Сравнительные рисунки на занятиях живописи разрабатываются в виде двух рисунков, созданных педагогом. Например, когда ученики знакомятся с воздушной перспективой педагог показывает два одинаковых рисунка пейзажа: первый - в котором присутствуют элементы воздушной перспективы и второй - в котором отсутствуют. По данным рисункам педагог подробно объясняет, какую роль играет определенный элемент изобразительной грамоты.

Чтобы разработать такой наглядный метод на занятиях живописи, педагогу необходимо обладать обширными знаниями в изобразительной грамоте. Должно быть отведено определенное время для создания таких сравнительных рисунков, чтобы довести до мышления учеников. Обладая искусствоведческими навыками, которые применяются для логического рассуждения и анализа работ сравнительного характера, можно разбирать с учениками их работы.

Живопись - это вид изобразительного искусства, который заключает в себе большое количество элементов изобразительной грамоты - линейная и воздушная перспективы, светотень, тоновой и цветовой контраст, рефлекс, холодный и теплый цвета, холодная и теплая гамма, цветовое единство, цветовой нюанс, колорит. Главным средством выразительности является цвет, с помощью, которого можно выделить индивидуальность, настроение, передать глубину и объем. «Цвет может лепить форму предмета, изображать 
красоту окружающего мира, выражать чувствам, настроения, определенное эмоциональное состояние» $[2$, с. 8$]$

Наука о цветах для начинающих художников не так уж и проста. Поскольку им немного известно о первичных и вторичных цветах. Как получить нужный цвет путем смешивания? Ведь цвет имеет три свойства: тон, яркость и насыщенность.

Используя цвет и его свойства в живописи также необходимо научиться определять цветовое и тоновое отношения. Изучение цветового и тонового отношения обязательно для начинающих художников. Демонстрация примерных живописных работ известных художников не являются достаточным. Учеников больше интересует как добиться того, чтобы правильно выполнить работу, используя правильное цветовое и тоновое отношения. Поэтому необходимо наглядно показать на сравнительных рисунках, где правильные тоновые и цветовые отношения, и, где нет правильного тонового и цветового отношения. Сравнительные рисунки по живописи помогут понять, как правильно находить тоновые и цветовые отношения в живописи.

Применяя наглядный метод, педагог должен использовать сравнительные рисунки и живописные работы известных художников, анализируя на доступном детям языке, нужно донести все элементы изобразительной грамоты, примененной выражении цвета и тона и в сравнительных рисунках и примерных произведениях. Используя такой метод, ученики вовлекаются познавательно-учебную деятельность.

Правильным решением изображения цвета и тона является применение цветового круга Иттена, который нам показывает, какие цвета первичные (желтый, красный, синий), вторичные (оранжевый, зеленый, фиолетовый) и третичные цвета (красно-оранжевый, желто-оранжевый, желто-зеленый, сине-зеленый, сине-фиолетовый, красно-фиолетовый). [1, с. 33]

При помощи цветового круга можно изучить какие цвета гармонируют в живописи. После изучения цветового круга (можно использовать и во время урока), идет изучение яркости и насыщенности. Затем, начинается изучения тонов (оттенков) цвета. Например, основной красный и его оттенки, после его изучения собираем постановку натюрморта в оттенках красного цвета (красная роза в прозрачной вазе и грейпфрут, а их фон украшен бордовой драпировкой). Тема цвета и тона должна красной нитью проходить через всю программу изучения живописи, т. е. с первого дня учебы. 


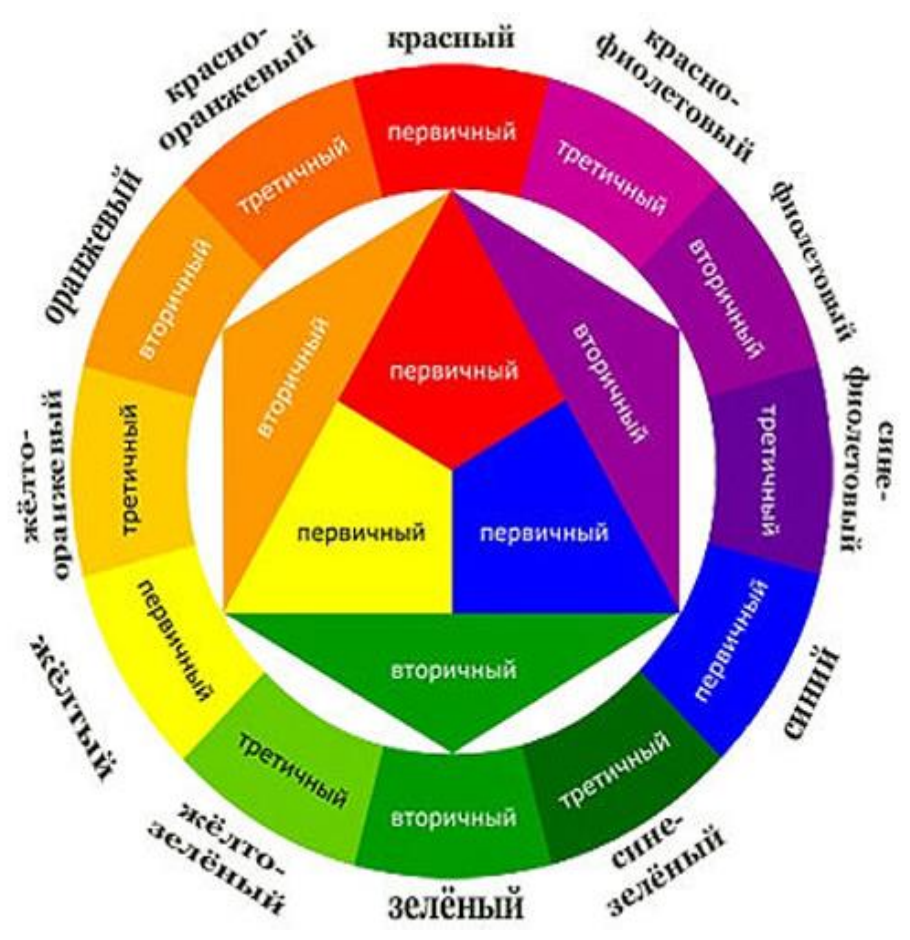

Рис. 1. Цветовой круг Иттена

Широко известные работы великих художников В.И. Сурикова, М.А. Врубеля, И.И. Шишкина, В.М. Васнецова, Ян Вермеера, Ван Гога и т.д., наглядно показывают, как выглядит работа, если правильно использовать средства выразительности. А сравнительные рисунки по данной теме, параллельно показывают разницу превосходств и недостатков.

Сравнительные рисунки помогают разобраться насколько важна изобразительная грамота, которая включает в себя и воздушную перспективу, и тоновое и цветовое решения, цветовое единство и т. д. Все это малопонятные элементы для неискушенного школьника, поэтому педагогу с учениками необходимо работать над ошибками, объяснять их причину, чтобы в дальнейшем не повторять их.

После полного освоения материала, педагог выставляет рисунки учеников «до» и «после» и описывает их результат. В итоге, школьники не только полностью осваивают материал и расширяют понятие роли и значимости изобразительной грамоты в живописи, но и научатся применять сделанные выводы в создании живописных работ. В дальнейшем, юные художники сами научатся анализировать творчество других и совершенствоваться сами.

Создавать сравнительные рисунки полезно не только в живописи, но и в рисунке и композиции. Используя наглядный метод в детской 
художественной школе обучение по живописи будет качественным и приведет к заметному творческому прогрессу учеников. Не зря говорил французский философ Рене Декарт «все познается в сравнении».

\section{Список литературы}

1. Иттен Иоханнес Искусство цвета / Пер. с немецкого; 13-е издание; Предисловие Л. Монаховой. - М.: Изд. Д. Аронов, 2020. - 96 с.; ил. ISBN 978-5-94056-047-0/

2. Сокольникова Н.М. Изобразительное искусство: Учебник для уч. 5 8 кл.: В 4 ч. Ч. 2. Основы живописи. - Обнинск: Титул, 1996. -80 с.: цв. ил.

3. Юсупхаджиева Т.В. Методика обучения и воспитания изобразительному искусству - г. Грозный, ЧГПУ. - Махачкала: АЛЕФ, 2018. $-92 \mathrm{c}$. 